\title{
On the action of nitric acid upon cholic acid
}

\section{A. Schlieper}

To cite this article: A. Schlieper (1846) On the action of nitric acid upon cholic acid, Philosophical Magazine Series 3, 29:194, 330-331, DOI: 10.1080/14786444608645511

To link to this article: http://dx.doi.org/10.1080/14786444608645511

册 Published online: 30 Apr 2009.

Submit your article to this journal

Џ Article views: 2

Q View related articles $₫$ 
Several analyses made according to this method yielded highly satisfactory results. $1 \cdot 771 \mathrm{grm}$. of recently ignited carbonate of potash, which was allowed to cool in a closed platinum crucible, gave 0.564 carbonic acid. Taking the atom of potash at 590 , that of the carbonic acid at $275,0.563$ ought to have been obtained.

$1.705 \mathrm{grm}$. of very pure magnesite gave 0.870 carbonic acid $=51.026$ per cent._-Poggendorff's Annalen, No. vi. 1846.

\section{ON THE ACTION OF NITRIC ACID UPON CHOLIC ACID. BY A. SCHLIEPF.R.}

The interesting connexion which has recently been shown to exist between the products of decomposition of cholesterine and choloidic acid by Prof. Redtenbacher*, led to the supposition that it might also extend to the other products of the bile if they were submitted to a similar treatment. With this view I have been induced to examine the action of nitric acid on Demarcay's cholic acid.

The cholic acid was prepared according to the process described by Theyer and Schlosser; bile, freed from mucus, fat and colouring substance, was retained for several days at a boiling temperature with a tolerably strong solution of potash, and then concentrated until a soapy mass, which became hard on cooling, separated from the liquid. After complete separation, it was dissolved in water, filtered, and treated with acetic acid, which separates the impure cholic acid in thick white flakes, which unite, forming resinous masses. If the eliminated resin be heated with water to boiling, it assumes all at once a granular crystalline structure, and is then easily reduced to powder; the latter was dried, and washed on a funnel with æther until it appeared white, and then pure white cholic acid obtained from it by dissolving and crystallizing it from alcohol. Cholic and nitric acids do not act on one another in the cold, however concentrated the latter may be ; but if a mixture of the two be heated in a retort, a very violent reaction soon ensues, the mass ascends, frothing considerably, while large quantities of nitrous acid escape. When the first action is over, the retort contains a dark yellow liquid, on which float some drops of oil, which on cooling solidify, and are nothing more than unaltered cholic acid. As the nitric acid which distilled over possessed a peculiar odour, it was nearly saturated with an alkali and again distilled; but although the aqueous distillate still retained the peculiar smell, none of the volatile products which Redtenbacher discovered in submitting cholesterine and choloidic acid to a similar treatment, could be detected in it. The yellowish liquid which remained in the retort was evaporated on the water-bath to expel the excess of nitric acid, when it dried to a yellowish transparent gum, which exhibited in its external properties the greatest resemblance to the cholesteric acid recently described by Redtenbacher. To separate this body from some still undecomposed cholic acid, it was repeatedly dissolved in water, filtered, and again evaporated until the residue dis- 
solved to a clear solution in water. To ascertain the presence of cholesteric acid, the silver salt was prepared by dissolving the acid gummy mass in water, neutralizing with ammonia, and precipitating with nitrate of silver; it was deposited in thick white tlakes. Oxalic acid was not present. To obtain the silver salt in a crystalline state, some nitrate of ammonia was added to the mother-ley from which it had been precipitated, in order to increase the solubility of the silver salt in it, then boiled with the precipitate, when the greater portion dissolved; on cooling, the cholesterate of silver separated from the hot filtered liquid, on the bottom and sides of the glass, in granular crystalline yellowish crusts; more of the salt was obtained by evaporating the mother-ley. The salt, dried at $212^{\circ}$, yielded 57.69 oxide of silver, 23.81 carbon, and 2.35 per cent. hydrogen; leading to the formula $\mathrm{AgO}, \mathrm{C}^{8} \mathrm{H}^{4} \mathrm{O}^{4}$, which is that of the cholesterate of silver.

The contemporaneous occurrence of cholesteric acid in the products of decomposition of choloidic acid, cholesterine and cholic acid by nitric acid exhibits the close relationship of these three bodies as respects their constitution.-Liebig's Annalen, lviii. p. 375 .

ON A NEW PROPERTY OF LIGH'T EXHIBITED IN THE ACTION

OF CHRYSAMMATE OF POTASH UPON COMMON AND POLARIZED LIGHT. BY SIR D. BREWSTER *.

The chrysammate of potash, which crystallizes in very small, flat rhombic plates, has the metallic lustre of gold, whence it derives its name of golden fluid. When the sun's light is transmitted through the rhombic plates it has a reddish yellow colour, and is wholly polarized in one plane. When the crystals are pressed with the blade of a knife on a piece of glass, they can be spread out like an amalgam. The light transmitted through the thinnest films thus produced, consists of two oppositely polarized pencils, - the one of a bright carmine red and the other of a pale yellow colour. With thicker films, the two pencils approach to two equally bright carmine red pencils. It is to the reflected light, however, and its new properties, that I wish to direct attention. Common light, reflected at a perpendicular incidence from the surfaces of the crystals, or of the films, has the colour of virgin gold. It grows less and less yellow as the incidence increases, till it becomes of a pale bluish white colour at very great incidences. The compound pencil, thus reflected and coloured, consists of two oppositely polarized pencils, - one polarized in the plane of reflexion, and of a pale bluish white colour at all incidences, and the other polarized perpendicular to the plane of reflexion, and of a golden yellow colour at small incidences, passing successively into a deeper yellow, greenish yellow, green, greenish blue, blue, and light pink, as the angle of incidence increases. This very remarkable property, which I have discovered also in some other crystals, is not caused by any film of oxide formed upon the natural surface of the crystal, nor is it the

* Read at the Southampton Meeting of the British Association. 